King Edward's Hospital Fund for London, 1988

Is the human embryo a human being in the full sense of those words, a human person? Is it an actual human person rather than (in some sense) a merely potential one? Unless these questions are answered satisfactorily it is hardly likely that the moral issues raised by embryo experimentation will ever be resolved; for to decide what sorts of things we may do to the embryo we first have to decide what the embryo is. The Status of the Human Embryo: Perspectives from Moral Tradition is a welcome attempt to give this issue the attention it deserves.

The book's contributors are members of a discussion group who have met regularly at King's College, London. They include medical practitioners, a biologist, a philosopher and theologians representing the Anglican, Catholic and Jewish moral traditions. Some essays are straightforward accounts of the nature of IVF techniques and related research, while others explore ethical aspects of IVF and embryo experimentation. Sir Immanuel Jacobovits's 'The status of the embryo in the Jewish tradition' is valuable in that it describes a moral and religious outlook which differs in important respects from Christian approaches. Fr Brendan Soane, in his 'Roman Catholic casuistry and the moral standing of the human embryo', discusses the official teaching of the Catholic Church and also the attitudes of contemporary moral theologians, some of whom question the official teaching. He points out that the Church has always condemned abortion as intrinsically evil, even though it has not formally declared that it is always a homicidal act. Before the nineteenth century it was commonly believed that the fetus was not 'formed', nor did ensoulment take place, until some time after fertilisation, so that an abortion performed before that time would not amount to the killing of a human person. It is surely much harder to defend this idea of delayed 'formation' or ensoulment now that we know that the genetic constitution of a human being is laid down once and for all at fertilisation and that what takes place after that is a process of continuous growth and maturation: as far as we can tell there are no sudden or radical 'leaps' in development which might indicate a point at which personhood would commence. The fact is that theologians commonly accepted delayed ensoulment on the authority of Aristotle and in ignorance of the embryological facts. It seems odd, then, to find Professor Gordon Dunstan, in his 'The human embryo in the Western moral tradition', urging that just because this theory of delayed ensoulment was adopted by Christian thinkers over a long period it deserves serious consideration today. In concentrating on this supposed tradition he neglects the real Christian moral tradition on this matter, namely that the deliberate destruction of the conceptus or fetus is always gravely wrong, regardless of whether or not it can be said to be 'formed' or 'ensouled'. The fact that ecclesiastical penalties for Catholics authorising or participating in the destruction of the unborn have sometimes varied according to the stage of development of the fetus in no way overthrows this conclusion.

Peter Byrne, in his article, 'The animation tradition in the light of contemporary philosophy', insists that we must face the question of the status of the human embryo, because 'only a decision about the personhood of the embryo will bring any clear sense of the obligations owed to it' (pages 90-91). He goes on to argue that any being which possesses human nature is ipso facto a human person: there is no criterion for human personhood apart from possession of 'mere' humanity. He argues: 'Now, that something has a rational [ie, human] nature does not entail that it must, in the present, display or possess in a realised form the capacitites of a rational life. The unconscious adult, the infant and the aged comatose or non-compos patient all possess the nature of rational beings. They share in rational nature even though they have lost or not yet acquired the present ability to express that nature' (page 95). One might naturally expect Bryne to apply this line of thought to the human fetus and embryo and urge that even the embryo possesses all the natural capacities and potentialities which belong to human nature, but that it has not yet developed to the stage at which it can exercise those capacities. On this view, the embryo would be a radically immature human being rather than a potential one. However, Byrne resists this idea and claims that the embryo is not an individual human being at all. He gives two main arguments for this conclusion: first, that it is impossible to pick out the embryonic matter which will eventually become the placenta and to distinguish it from the embryo proper; and secondly, that until the possibility of twinning has been excluded, at around 14 days, we cannot say that there is a definite individual present. Neither of these arguments is defended at any length, and Byrne seems not to suspect that those who recognise the embryo as an individual human person from the moment of fertilisation might have replies to them. But such replies are certainly available. For instance, the fact that the embryo is 'programmed' to produce an organ, the placenta, which is eventually discarded hardly shows that it (the embryo) was not a human being from the beginning; while, with regard to twinning, it could be that what is present immediately after fertilisation is a single, individual embryonic human being which later reproduces itself asexually. Byrne, like Dunstan, clearly fails to consider possible objections to his line of argument. This failure to reckon with opposing standpoints and arguments is a definite shortcoming of this volume, despite its evident interest and value.

F J FITZPATRICK Education and Research Officer, The Linacre Centre for the Study of the Ethics of Health Care,

\section{The Sociology of Health and Healing}

Margaret Stacey, 298 pages, London, $£ 30.00 \mathrm{hbk}, £ 12.95 \mathrm{pbk}$,

Unwin Hyman, 1988

Sociology is open to criticism for sprawling vaguely across many disciplines. This imprecision has advantages when broad issues are being examined, such as health and healing which involve almost every aspect of knowledge, experience and morality. Margaret Stacey amply demonstrates the breadth and depth of understanding which a sociological examination of healing offers.

This book draws on Professor Stacey's twenty-five years of researching and teaching, as well as her work with health care pressure groups, and on the Welsh Hospital Board and the General Medical Council. Her work is practical in that it aims to achieve a clearer understanding of actual experiences of health care. The language is jargon-free so that this work can be directly useful to readers from many disciplines.

The first part of the book reviews health care in Europe over the last four centuries. This enables the reader, 
during part two, to see the issues for our society today in a richer context, and it also shows the sense and logic underlying different systems of health care. The result is a far more critical and penetrating analysis of health and morality than is possible within conventional medical ethics which shares (instead of questioning) so many assumptions of conventional medicine. Basic questions, such as, 'What is efficacious?' extend into the questions: 'Efficacious in whose terms? For what purpose? To what end?' and a wealth of evidence provides many detailed answers.

Margaret Stacey sees close connections between health care and morality. 'The ways in which a society copes with the major events of birth, illness and death are central to the beliefs and practices of that society and also bear a close relationship to its other major social, economic and cultural institutions. In particular, the treatment of those who are dependent on others is a revealing indicator of the social values lying behind the allocation of resources. This being so, understanding the beliefs and practices associated with health and healing contributes to a deeper understanding, of the society in which they are found.'

When health care is related to its social setting, it is clear that we all share in the work of creating and sustaining health. 'Preventive' health care is a negative term for this creative work. Chapters are devoted to lay concepts of health, alternative healing systems, the many different kinds of paid health workers, and to the two largest groups, the unpaid health workers who are patients and carers.

Perhaps the most valuable contribution of this book is that alongside the summaries of the usual, widely accepted accounts there is a continuous commentary from women. The women's views dramatically illustrate how one-sided discussions of health are, being almost entirely by men and for men. Just one, from many examples, is how health visiting began in order to regulate 'feckless' mothers. Yet the women needed not advice, but practical help in coping with poverty, totally inadequate diet, and childbearing while already trying to care for too many children and often with heavy work outside the home as well. Health insurance only covered working men, not their families. In 1915 the Women's Co-operative Guild published evidence of these burdens and called for political change not philanthropy. I suggest that this radical response, informed by listening seriously to the people concerned, demonstrates far more respect for personal autonomy than abstract philosophising can ever do.

The framework of analysis developed through the book culminates in the final chapter on reproduction to present the viewpoints of women who, although most intimately affected, are usually least heard. If this book were required reading for ethicists, medical ethics in the 1990 s could be considerably wiser.

PRISCILLA ALDERSON Research Officer

Westminster Children's Hospital London

\section{Freud, Insight and Change}

Ilham Dilman, 245 pages, Oxford, $£ 25.00$, hbk, Basil Blackwell, 1988.

Insight-orientated psychotherapies all seek to effect beneficial change through the attainment of personal insight by the therapee. The assumption that greater self-understanding can bring about curative change is fundamental to all such approaches. But what is the nature of 'insight', how is it attained, and how does it lead to personal change? These are the core questions which Professor Dilman sets out to elucidate in his latest contribution to the philosophy of psychoanalysis. Classical psychoanalysis, which is both a theory of human psychology and a mode of therapuetic praxis, is the progenitor of all insight-directed therapies. Two previous books by Professor Dilman have focussed upon the Freudian account of mind and human nature. The present work takes psycho-analysis as therapy as its field of enquiry. Proceeding from Freud's own writing on the subject a conceptual analysis of such key notions as 'free association', 'insight' and 'self-control' is undertaken. Through this analysis an account of the nature of insight and of personal change through the attainment of insight is generated.

Greater insight isn't simply a matter of holding extra true beliefs about oneself. Rather it is the direct recognition, under a new aspect, of some pattern in one's affective and cognitive responses. This is what it is to 'make conscious the unconscious'. And because gaining insight is coming to own thoughts and feelings which were previously unacknowledged it involves some degree of personal change.
Although the responses remain the same, one's conscious attitude to what makes them is enlarged by one's new awareness of the nature of these responses. It follows that insight cannot be imparted simply by telling the therapee some hitherto unacknowledged facts about himself. Insight is obtained through the elimination of resistances in the movement of therapy. This in turn depends upon a general desire for authenticity: the desire to be what we are and to be accepted as such.

Dilman calls the attainment of insight 'the enlargement of consciousness' and distinguishes it from the 'enlargement of self which is the outcome of the inner change which may be consequent upon gaining insight. He evokes the idea of a 'healing process' which can operate on what is made conscious and bring about the resolution of inner conflicts and difficulties. The 'healing process' is the following through of certain normal affective responses which may themselves involve experiencing fear and anxiety. These normal processes of psychological resolution are blocked when mechanisms of repression are invoked to avoid having to confront these anxieties and fears. Insight removes these blocks and allows the normal resolving processes to go ahead. Repenting, forgiving, giving up idealisations and denigrations, and mourning are instances of these 'healing' psychological processes.

Dilman also addresses the question of values in psychoanalytic therapy. $\mathrm{He}$ argues that there is a moral orientation within the psychoanalytic approach which values greater authenticity, autonomy, respect and care for others, and the ability to form relationships of affection, loyalty and friendship. He acknowledges that curative changes in therapy are regarded as being those in the direction of the realisation of these values. Psychoanalytic therapy is not concerned to proselytise for these values, but progress in therapy requires a desire for greater authenticity, and a concomitant willingness to be honest with oneself and with the therapist. Curative changes in therapy involve an ethical transformation in the direction of giving a greater centrality to these values, but it is a condition of such change that these values are already entertained by the therapee.

The book is written in a clear and persuasive style, and its argumentation is available to the non-philosopher and to those unacquainted with psychoanalytic theory. There are, however, too many references at difficult points in the argument to 